\title{
Designing an Engineer-To-Order Performance Measurement System: A Case Study
}

\author{
Børge Sjøbakk and Ottar Bakås \\ SINTEF Technology and Society, Industrial Management \\ P.O. Box 4760 Sluppen, N-7465 Trondheim, Norway \\ \{borge.sjobakk, ottar.bakas\} asintef.no
}

\begin{abstract}
The conventional maxim of "what gets measured gets done" has motivated many companies to systematically measure their performance over the years. From previously being focused solely on financial, backward-looking measures, it is now generally agreed that a performance measurement system (PMS) should align with a company's long-term, strategic objectives. These objectives are largely dictated by the company's production situation, and vice versa. When being approached by a Norwegian engineer-to-order (ETO) company requesting a PMS, the authors could not identify any literature explicitly referring to PMS for ETO. The authors therefore set out to design the PMS from scratch. The purpose of this paper is to illustrate how the PMS was designed in close collaboration with the case company, bearing the general characteristics and competitive priorities of ETO in mind.
\end{abstract}

Keywords: Performance measurement system, design methodology, engineerto-order.

\section{Introduction}

There is a variety of production situations that can be used to meet demand. Most of the operations management and production literature would classify companies into a manufacturing continuum spanning across four types, depending on the position of the customer order decoupling point (CODP): make-to-stock (MTS), assemble-toorder (ATO), make-to-order (MTO) and engineer-to-order (ETO) [1]. In the ETO production situation products are manufactured to meet a specific customer's needs by unique engineering or significant customization [1]. The products are often complex, with deep structures consisting of both customized and standardized components [2]. Further, uncertainty in product- and process specifications, product mix and -volume $[3,4]$ often results in high lead times [5] and frequent change orders [6].

The competitive priorities of a company are largely dictated by its production situation, and vice versa. This should be reflected in the company's performance measurement system (PMS), i.e. the set of metrics used to quantify both the efficiency and effectiveness of actions [7]. Performance measures should focus on the order winners and market qualifiers for the different processes up- and downstream of the CODP [8]. This implies that the design of a company's PMS should vary with its 
production situation, and that a PMS for ETO in some way would differ from a PMS for MTS-, ATO- or MTO. For example, flexibility is regarded as an order winner in ETO, as opposed to price, which is more important in the MTS production situation [9]. As such, flexibility would necessarily have to be emphasized more in a PMS for ETO.

When being approached by a Norwegian ETO company requesting a PMS, the authors initially set out to identify what was already written about PMS for ETO. In this respect, quite a bit of literature on performance measurement in construction, which has the same discontinuity aspects of temporariness, uniqueness and multifunctionality as those found in ETO [10], was identified [e.g. 11, 12-15]. However, as noted by Beatham et al. [11] construction performance measures are often lagging measures used mainly as a marketing tool rather than as means for improvement. In ETO, a considerable portion of the manufacturing and assembly processes are carried out at the corporate premises using a production system managed according to established manufacturing policies, unlike the often 'ad hoc' construction projects [10]. As such, there would arguably be elements of repetition in ETO that could be measured using a more complete PMS consisting of both leading and lagging indicators. This PMS could be used as a means for improving the production system and its policies.

No literature explicitly referring to PMS for ETO was identified. The authors therefore set out to design the PMS from scratch, taking a PMS design methodology by Andersen and Fagerhaug [16] as a starting point due to their familiarity with this approach. The purpose of this paper is to illustrate how the PMS was designed in close collaboration with the case company, bearing the general characteristics and competitive priorities of ETO in mind. The focus lies at the process of designing the PMS rather than the details of the final PMS.

The remainder of the paper is structured as follows: First, the research method and case company are described. This is followed by some theoretical background, before the process of designing the PMS is described. Finally, the findings are concluded.

\section{Research Method}

The research was carried out by a qualitative approach, utilizing the action research method. Action research seeks to generate new knowledge both for the problem holder (in this case the ETO company) and the action researchers, through collaboratively solving problems in real life situations while having a research interest in mind [17, 18]. This research method is different from many other methods in that the researchers actively take part in the context of their research area, shaping a mutual reliance on the problem holder's and the researchers' skills and competences $[17,18]$. Due to its nature, action research and its practitioners have met various types of critique over the years: It has been claimed to be nothing more than consultancy in not emphasizing the research in a sufficient (scientific) manner [18]; it is claimed to be inadequate in safely making causal inferences [19]; and, the researchers are said to be especially exposed for bias [18]. Further, it is prone to general critique of qualitative research; that it is hard to generalize from this type of research design, and it that it therefore lacks some key criteria for research quality [18]. The authors acknowledge that the 
idiosyncratic context of working closely with the problem holder restricts the possibility to fully generalize and replicate the research and its results. However; close collaboration was a critical success factor as the PMS needed to be tailored to the company. By investigating the requirements for a PMS for ETO, the research interest was also maintained, as this is a topic that has received little attention in the literature.

About the Problem Holder. The problem holder is a relatively small, high-tech company that specializes in design, manufacturing, technological development, installation and support of solutions for environmental monitoring. While being part of a larger international group, this particular subsidiary has its main office in the middle of Norway. For the PMS design activity, the production of ocean monitoring platforms was chosen as a case. These contain sensors for measuring various parameters, e.g. meteorological data and water quality. The platforms are categorized in four types based on different sizes and shapes of the floaters. There are some components that are common for all platforms, e.g. data loggers, floater (though different for each platform type) and electronics. Besides this, the platforms can be customized to a large extent. For each single platform that is delivered, the company has to engineer an anchorage system based on the seabed conditions in its area of operations. The production of a platform is triggered by a customer order, often resulting from tendering as the company has a high share of public customers. As is evident, the characteristics of the company coincide with typical characteristics of ETO, making it an interesting case for the design of a PMS for ETO.

\section{Theoretical Background}

The conventional maxim of "what gets measured gets done"1 has motivated many companies to systematically measure their performance over the years. Earlier, performance was typically measured in terms of one or several financial ratios collectively suggesting how well a company was doing [20]. However, since the 1980s and 1990s other non-financial factors contributing to the performance of organizations have gained ground [16]. For example, in their balanced scorecard approach Kaplan and Norton [21] augment traditional financial measures with performance measures in the three areas of a company's relationship with its customers; its key internal processes; and, its learning and growth - arguing that financial measures and targets are not sufficient in measuring performance against a company's long-term strategic objectives. Today, it is generally agreed that performance measures should be derived from a company's strategic priorities [22].

There exist a lot of general methods for designing a PMS [e.g. 7, 16, 22]. Andersen and Fagerhaug [16] present an eight-step methodology: (1) Understanding and mapping business structures and processes; (2) developing business performance

1 Peters and Waterman attribute it to the organization theorist Mason Haire. In: Peters, T., Waterman, R.H.: In search of excellence: lessons from America's best-run companies. Harper \& Row, New York (1982) 
priorities; (3) understanding the current PMS; (4) developing performance indicators; (5) deciding how to collect the data; (6) designing reporting and performance data presentation formats; (7) testing and adjusting the PMS; (8) implementing the PMS.

To assess organizational goal attainment, performance indicators play an important role in a PMS. A performance indicator is a variable that expresses quantitatively the effectiveness or efficiency (or both) of (part of) a process or system against a given norm or target [23]. Over the years, the list of available performance indicators has grown extensively, and for many companies step 4 in the methodology by Andersen and Fagerhaug [16] may be more a task of 'deciding' rather than 'developing' performance indicators. Further companies should decide on a few key performance indicators (KPIs), i.e. a set of performance indicators focusing on the aspects of an organization's performance that are most critical for the organizations present and future success [24], in order to make reporting and follow-up manageable.

Finally, the purpose of having a PMS generally exceeds that of "getting things done". Other stated purposes include motivation, promotion, celebration, learning and improvement, and performance measures should be chosen accordingly [20].

\section{Designing the Performance Measurement System}

In designing a PMS for the problem holder, the methodology by Andersen and Fagerhaug [16] was taken as a starting point; however, it was not followed to the letter. First, the company's current PMS was mapped, referring to Step 3 in the methodology. Thereafter, five workshops with different departments in the company generated suggestions for necessary performance indicators, which were further refined by the researchers (Step 4). In this process, a brief evaluation of the measurability of the different indicators was carried out (Step 5). A preliminary set of performance indicators was then sent out to the management and other parts of the company for feedback. In this way a top-down cascading method was combined with a bottom-up design process, which is in line with what Andersen and Fagerhaug [16] recommend.

Aligning the PMS with the Problem Holder's Strategic Priorities. As noted in theory, a PMS should be derived from a company's strategic priorities. When the researchers were approached by the problem holder, the company had formulated a vision in its management system; however, it was agreed that it needed to be made easier to communicate both internally and externally. This realization served as an opportunity to rethink and reformulate the company's strategic priorities into something shorter and easier to remember for all stakeholders. Based on their experience with the company, the researchers were able to propose a vision and five strategic business goals with which the PMS could be aligned (Step 2). The strategic business goals were: (1) Safe and stimulating workplace; (2) efficient delivery; (3) high quality products and services; (4) preferred partner; and (5) sustainable production. In order to ensure balance of the PMS and measurements of relevance, these strategic business goals were further itemized into the following measurement dimensions: Customer focus; flexibility; safety; people; delivery time; delivery precision; quality; innovation 
and R\&D; financial performance; and environment. Most of these dimensions would prove valuable for all production situations; however, flexibility, innovation and R\&D are especially important for ETO due to the production situation's high product complexity and uncertainty in specifications and demand.

Workshops were carried out to secure the company's ownership to the new vision, strategic goals and measurement dimensions. As such, a byproduct of the PMS design process was that the researchers and the problem holder together developed a new vision for the company - concretizing its strategic priorities.

Understanding the Business Environment. The aforementioned workshops were further used to ensure that the main activities of the company were understood correctly (Step 1). These were structured in five business processes: (1) Sales; (2) planning; (3) engineering; (4) source and make; (5) delivery. Interestingly, the problem holder illustrated this as a 'customer journey', which in a neat way links the order-driven ETO business processes, the business functions responsible for each process and inherent handover activities (Fig. 1). This is important for the use and follow-up of the PMS, as this should be distributed over the many business functions involved in ETO production, with especially planning and engineering arguably being more important in ETO than in other production situations due to all operations being order-driven and the share of engineering done to every product.

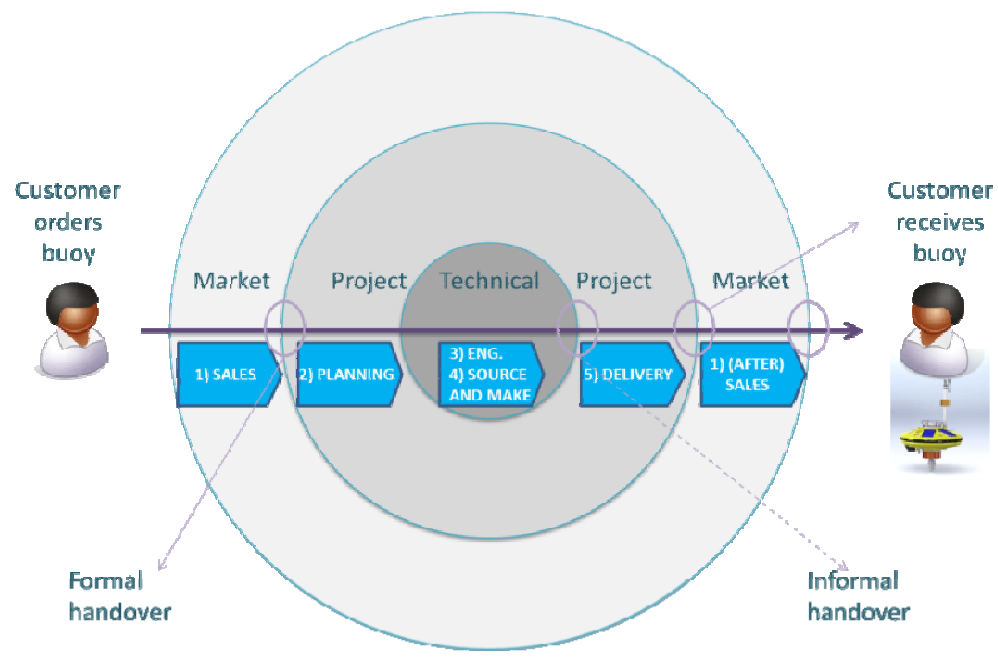

Fig. 1. The 'customer journey' showcasing responsibilities and handovers

From PIs to KPIs. During the workshops with the problem holder, 57 potential performance indicators were identified. For each indicator, the following was described: (1) Name and link to associated measurement dimension; (2) definition, i.e. a formula for calculating the performance; and (3) motivation, i.e. a description of its relevance. In collaboration with the case company, the performance indicators (PIs) were 
structured in accordance with the business processes of the company, as outlined in the customer journey: Sales (10 PIs); planning (6 PIs); engineering (10 PIs); source and make (13 PIs); delivery (9 PIs). Several indicators were found to occur in every process. These were gathered in a separate group coined 'common for all' (9 PIs). Both project- and production oriented indicators were considered in this process.

Based on the large number of relevant performance indicators, a limited set of KPIs was created to make the PMS more manageable. Such KPIs should in a simple and intuitive way display the current status in locations readily available for all employees, for example through a traffic light system. The KPIs should be easily linked with their underlying information in a drill-down manner. The previously developed strategic business objectives and measurement dimensions guided the task of creating KPIs, which were compound indexes calculated based on the status of underlying PIs. For example, the preferred partner index is aggregated based on the status of three underlying PIs: customer satisfaction measurement, percentage of re-sales to existing customers and tendering hit-rate.

Fig. 2 below illustrates the connection between the vision, the strategic business goals, the measurement dimensions, the business processes and the key performance indicators.

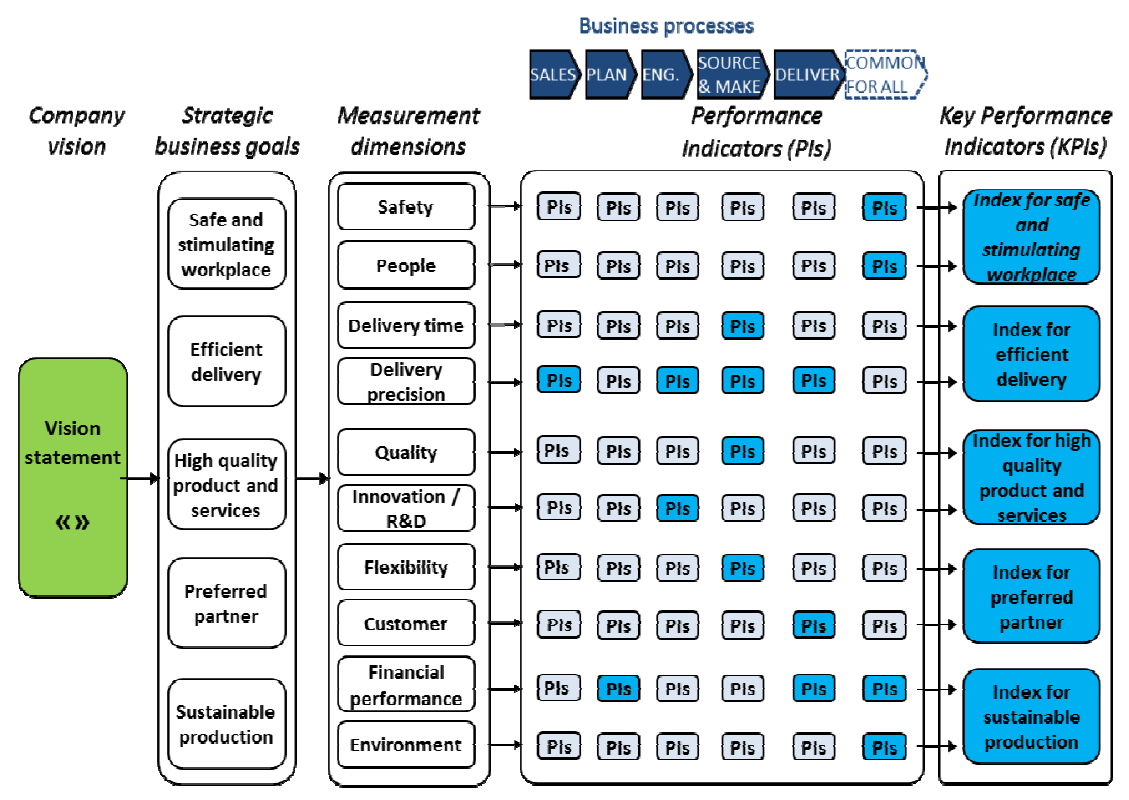

Fig. 2. Structural overview of PMS

Last, principles for implementation were described. The following five factors were described as vital: (1) Setting targets; (2) identifying measurement methods; (3) setting the frequency of registration and reporting; (4) principles for visualization; and (5) responsibility for measurement and follow-up. 


\section{Conclusion}

The complex process of designing a PMS requires structure and methodology. Even though a step-wise waterfall model by Andersen and Fagerhaug [16] was applied, the researchers experienced going back-and-forth in the design process. To ensure that the PMS was derived from the company's strategic priorities in a consistent and integrated manner, four principles were applied: (1) Define strategic business goals supporting the company's vision; (2) construct measurement dimensions covering the strategic business goals; (3) relate performance indicators to business processes and measurement dimensions; (4) ensure that KPIs cover all measurement dimensions. Involving employees and managers from main business functions is critical.

The design process itself provided several unforeseen side effects. First, the 'customer journey' was found to be a helpful tool to structure the business processes and -functions within the company. Second, the PMS design process can serve as a catalyst for clarifying the vision and strategic objectives of the company. Third, the process can spur a number of improvement suggestions to existing processes and procedures.

Feedback from the problem holder supports the usefulness of the proposed PMS. However, as it has not yet been fully implemented at the company any numerical data to quantitatively assess its effects has not yet been made available. The researchers acknowledge that the findings are based on a single case, and that working closely with the problem holder limits the generalizability of the research and its results. Nonetheless, the case should be useful for others struggling to design their own PMS.

The topic of designing a performance management system for ETO companies is an area with much potential for further research, having received little attention in academic literature. The researchers therefore call for more studies describing the design process itself, and the actual resulting performance indicators that should be tailored to customer-specific and engineering-oriented production situations. Finally, as these may vary significantly, a minimum stability or degree of repetition required for an ETO company to fully exploit a PMS should be identified.

Acknowledgements. This work has been conducted within the MARGIN project (Integrated and responsive maritime supply chains) funded by the Regional Research Fund Mid-Norway and the SFI Norman (Norwegian Manufacturing Future) programme supported by the Research Council of Norway. The authors would like to thank the participants of the projects for providing valuable empirical data.

\section{References}

1. Amaro, G., Hendry, L., Kingsman, B.: Competitive advantage, customisation and a new taxonomy for non make-to-stock companies. Int. J. Oper. Prod. Man. 19, 349-371 (1999)

2. Hicks, C., McGovern, T., Earl, C.: Supply chain management: A strategic issue in engineer to order manufacturing. Int. J. Prod. Econ. 65, 179-190 (2000) 
3. Bertrand, J., Muntslag, D.: Production control in engineer-to-order firms. Int. J. Prod. Econ. 30, 3-22 (1993)

4. Muntslag, D.R.: Profit and risk evaluation in customer driven engineering and manufacturing. Int. J. Prod. Econ. 36, 97-107 (1994)

5. Pandit, A., Zhu, Y.: An ontology-based approach to support decision-making for the design of ETO (Engineer-To-Order) products. Automat. Constr. 16, 759-770 (2007)

6. Riley, D.R., Diller, B.E., Kerr, D.: Effects of delivery systems on change order size and frequency in mechanical construction. Journal of Construction Engineering and Management 131, 953-962 (2005)

7. Neely, A., Gregory, M., Platts, K.: Performance measurement system design: A literature review and research agenda. Int. J. Oper. Prod. Man. 15, 80-116 (1995)

8. Olhager, J.: Strategic positioning of the order penetration point. Int. J. Prod. Econ. 85, 319-329 (2003)

9. Olhager, J., Rudberg, M., Wikner, J.: Long-term capacity management: Linking the perspectives from manufacturing strategy and sales and operations planning. Int. J. Prod. Econ. 69, 215-225 (2001)

10. Caron, F., Fiore, A.: 'Engineer to order'companies: How to integrate manufacturing and innovative processes. International Journal of Project Management 13, 313-319 (1995)

11. Beatham, S., Anumba, C., Thorpe, T., Hedges, I.: KPIs: A critical appraisal of their use in construction. Benchmarking: An International Journal 11, 93-117 (2004)

12. Chan, A.P., Chan, A.P.: Key performance indicators for measuring construction success. Benchmarking: An International Journal 11, 203-221 (2004)

13. Takim, R., Akintoye, A.: Performance indicators for successful construction project performance. In: 18th Annual ARCOM Conference, pp. 545-555 (Year)

14. Robinson, H.S., Carrillo, P.M., Anumba, C.J., A-Ghassani, A.: Review and implementation of performance management models in construction engineering organizations. Construction Innovation: Information, Process, Management 5, 203-217 (2005)

15. Navon, R.: Research in automated measurement of project performance indicators. Automat. Constr. 16, 176-188 (2007)

16. Andersen, B., Fagerhaug, T.: Performance Measurement Explained: Designing and Implementing Your State-of-The-art-System. ASQ Quality Press, Wisconsin (2002)

17. Greenwood, D.J., Levin, M.: Introduction to action research: social research for social change, Thousand Oaks, California, Sage (2007)

18. McKay, J., Marshall, P.: The dual imperatives of action research. Information Technology \& People 14, 46-59 (2001)

19. Baskerville, R.L., Wood-Harper, A.T.: A critical perspective on action research as a method for information systems research. J. Inform. Technol. 11, 235-246 (1996)

20. Behn, R.D.: Why measure performance? Different purposes require different measures. Public Admin. Rev. 63, 586-606 (2003)

21. Kaplan, R.S., Norton, D.P.: Using the balanced scorecard as a strategic management system. Harvard Bus. Rev. 74, 75-85 (1996)

22. Bourne, M., Mills, J., Wilcox, M., Neely, A., Platts, K.: Designing, implementing and updating performance measurement systems. Int. J. Oper. Prod. Man. 20, 754-771 (2000)

23. Fortuin, L.: Performance indicators - why, where and how? Eur. J. Oper. Res. 34, 1-9 (1988)

24. Parmenter, D.: Key performance indicators (KPI): Developing, implementing, and using winning KPIs. John Wiley \& Sons (2010) 